\title{
A Motivação Intrínseca e o Estado Mental Flow em Corredores de Rua ${ }^{1}$
}

Fábio Luiz Massarella*

Pedro José Winterstein ${ }^{* *}$

\begin{abstract}
Resumo: Participaram do estudo qualitativo, dez praticantes de corrida de rua. A metodologia utilizada foi a análise de conteúdo. A maioria dos praticantes iniciou a atividade extrinsecamente motivada, mas a motivação intrínseca mostrou-se determinante na permanência por muitos anos. Identificamos relações entre os temas levantados na análise e os elementos que caracterizam o estado mental flow. Esses elementos podem ser importantes direcionadores na estruturação de atividades físicas, mantendo o indivíduo intrinsecamente motivado, implicando maior assiduidade, empenho, tempo de permanência e satisfação.
\end{abstract}

Palavras-chave: Psicologia. Esportes. Corrida. Motivação. Estado Mental Flow.

\section{INTRODUÇÃO}

A corrida pedestre é uma modalidade esportiva muito praticada atualmente. É comum vermos pessoas correndo por ruas, praças, parques e avenidas. As provas de corrida de rua se tornaram eventos populares e têm apresentado rápido crescimento em quantidade e qualidade. Atletas de elite participam de algumas provas e são atração, mas constituem um número pequeno diante da massa de corredores amadores, pessoas que encontram nas corridas de rua uma forma saudável de lazer, integração social e manifestação pessoal através do esporte.

O comportamento humano é bastante complexo, mas teorias sobre motivação podem nos ajudar a compreendê-lo. Uma pessoa

\footnotetext{
${ }^{1}$ Este artigo é resultado de Dissertação de Mestrado realizado na Faculdade de Educação Física da UNICAMP.

"Mestre do Laboratório de Psicologia do Movimento Humano. UNICAMP. Campinas, SP, Brasil. E-mail: fabiomassarella@yahoo.com.br

** Professor Doutor do Laboratório de Psicologia do Movimento Humano. Faculdade de Educação Física. UNICAMP. Campinas, SP, Brasil. E-mail: winterstein@fef.unicamp.br.
} 


\section{Artifor Orifimais Fábio Massarella e Pedro Winterstein}

pode se envolver com alguma atividade, motivada extrínseca ou intrinsecamente. Quando a motivação é extrínseca, a atividade constitui apenas um meio para atingir um objetivo externo, como dinheiro ou status, e esse tipo de motivação, geralmente resulta em maior tensão e pressão e em níveis mais elevados de ansiedade e estresse. Quando a motivação é intrínseca, as pessoas não estão focadas em recompensas, elas podem vir, mas como consequência do envolvimento e empenho. Esse tipo de motivação está associado geralmente a comportamentos mais estáveis e duradouros. Também pode levar as pessoas a experimentarem um estado mental diferenciado chamado flow, em que o envolvimento pleno com a atividade e com o momento presente resulta numa sensação de prazer e satisfação únicos e de grande significado pessoal. A vivência de experiências desse tipo pode contribuir para que as pessoas se engajem efetivamente na prática de alguma atividade física ou esportiva.

$\mathrm{O}$ estudo de que trata este artigo buscou identificar, nos praticantes de corrida de rua, quais os motivos subjacentes à escolha dessa atividade como modalidade esportiva ou prática de lazer; que tendência motivacional eles apresentavam (intrínseca ou extrínseca); que sentimentos e que pensamentos eram percebidos durante a prática e se possuíam alguma semelhança com as descrições dos elementos do flow de Csikszentmihalyi.

\section{As CORRIDAS DE RUA}

No Brasil, a corrida de rua é um segmento do atletismo e a CBAt (Confederação Brasileira de Atletismo), é a associação que a regulamenta, organiza e coordena. Atletas de elite (que atingem índices mínimos de tempo estabelecidos e têm participação formal no atletismo) participam de provas juntamente com milhares de corredores amadores, que correm para manter certo nível de aptidão física e por lazer (CBAt, 2007). Em grande parte das corridas de rua realizadas no Brasil, o percurso é de $10 \mathrm{Km}$, mas existem provas tradicionais com percursos maiores, como $15 \mathrm{Km}$, meia maratona $(21,097 \mathrm{Km})$ e maratona $(42,195 \mathrm{Km})$. Algumas também têm percursos com distância menor ou caminhada, permitindo, assim, que familiares dos corredores

Movimento, Porto Alegre, v. 15, n. 02, p. 45-68, abril/junho de 2009. 
também participem do evento. Geralmente, há a participação tanto de homens quanto de mulheres. A idade mínima permitida normalmente é de 16 anos, com autorização dos pais ou responsáveis, e há eventos em que também é possível a participação de deficientes físicos.

\section{MotivaÇão NO ESPORTE E NA ATIVIDADE FísICA}

As pessoas podem praticar certa modalidade esportiva ou atividade física por diversos motivos. Para Weinberg e Gould (2001, p. 79), "a motivação é a variável-chave tanto na aprendizagem como no desempenho em contextos esportivos e de exercícios". A permanência, a intensidade com que se dedica e os resultados que o sujeito alcança são influenciados por sua motivação, independentemente de estar ou não no esporte de alto rendimento, embora outros fatores possam também interferir no desempenho, como nível de ansiedade, estresse, condicionamento físico, saúde etc.

Embora as pessoas possam se empenhar na realização de uma atividade por vários motivos, há casos em que elas se envolvem com atividades que as mantêm interessadas em sua realização, sentindose motivadas a repeti-las mais vezes. A teoria da motivação intrínseca surgiu para explicar o comportamento de pessoas que gastam muito tempo em determinadas atividades sem uma recompensa externa evidente. As recompensas, nesse caso, são inerentes à atividade, ligadas aos sentimentos positivos vivenciados. Por outro lado, se a tarefa for realizada na expectativa de recompensas externas, o indivíduo está extrinsecamente motivado. A relevância desse conceito é que a motivação extrínseca tende a deteriorar. Uma vez satisfeita a necessidade ou atingido o alvo extrínseco, a motivação intrínseca tem tendência de ser mais constante (MASSARELLA; WINTERSTEIN, 2005, p. 2).

Vallerand (2001) propôs um modelo hierárquico de motivação intrínseca, extrínseca e amotivação (que é a relativa ausência de motivação), ele esclarece que as pessoas não são motivadas unicamente intrínseca ou extrinsecamente, nem amotivadas, elas normalmente apresentam os três tipos de motivação em diferentes graus. A motivação

Movimento, Porto Alegre, v. 15, n. 02, p. 45-68, abril/junho de 2009. 
deve ser considerada em nível situacional (o momento), contextual (o entorno) e global (o comportamento normalmente apresentado).

Para Csikszentmihalyi (1999), quando estamos concentrados em uma tarefa, formamos uma intenção, estabelecemos uma meta. $\mathrm{O}$ tempo que dedicamos a essa meta e a intensidade com que a mantemos dependem de nossa motivação. As pessoas demonstram se sentir melhor quando agem motivadas intrinsecamente, mas ainda demonstram se sentir melhor quando motivadas extrinsecamente do que quando agem amotivadas, por não ter nada melhor para fazer.

Um sólido conjunto de metas nos ajuda a desenvolver um self coeso e é determinante para nossa autoestima. Os sentimentos que temos a nosso respeito e a alegria que experimentamos por estarmos vivos dependem de como nossa mente filtra e interpreta as experiências. Nossa felicidade depende mais de nossa harmonia interior que do controle que exercemos sobre eventos externos (CSIKSZENTMIHALYI, 1992).

\section{A TEORIA do FLoW}

A teoria do "flow" surgiu dos estudos do Psicólogo americano Mihaly Csikszentmihalyi. Segundo Weinberg e Gould (2001, p. 158), ela representa uma inovação nos estudos sobre motivação intrínseca. As pesquisas envolvendo essa teoria têm evoluído bastante em países como Estados Unidos, Canadá, Alemanha, Itália, Japão e Austrália, mas, no Brasil, há relativamente poucos estudos. O conceito de flow é derivado do estudo de atividades que Csikszentmihalyi considerou intrinsecamente motivantes, que proporcionam prazer em sua realização e, por isso, levam o indivíduo a um estado de profundo envolvimento e a ter um sentimento intenso de alegria e satisfação pessoal.

Para Csikszentmihalyi (1988, 1992, 1999), oflow acontece em condições específicas, quando a atenção está totalmente focada na atividade e sentimentos, desejos e pensamentos estão completamente alinhados. Foram identificados oito elementos que definem essa experiência: equilíbrio entre desafio e habilidade; metas claras e retorno (feedback); concentração total na atividade e no momento presente;

Movimento, Porto Alegre, v. 15, n. 02, p. 45-68, abril/junho de 2009. 
fusão entre ação e consciência; sensação de controle; perda da autoconsciência; perda da noção do tempo; experiência autotélica. Quando as pessoas refletem sobre o que sentem quando vivenciam uma experiência muito positiva, elas mencionam pelo menos um desses oito elementos.

- Equilíbrio entre desafio e habilidade: há um equilíbrio entre o desafio com o qual o sujeito está envolvido e sua capacidade de responder a ele de forma adequada (Figura 1).

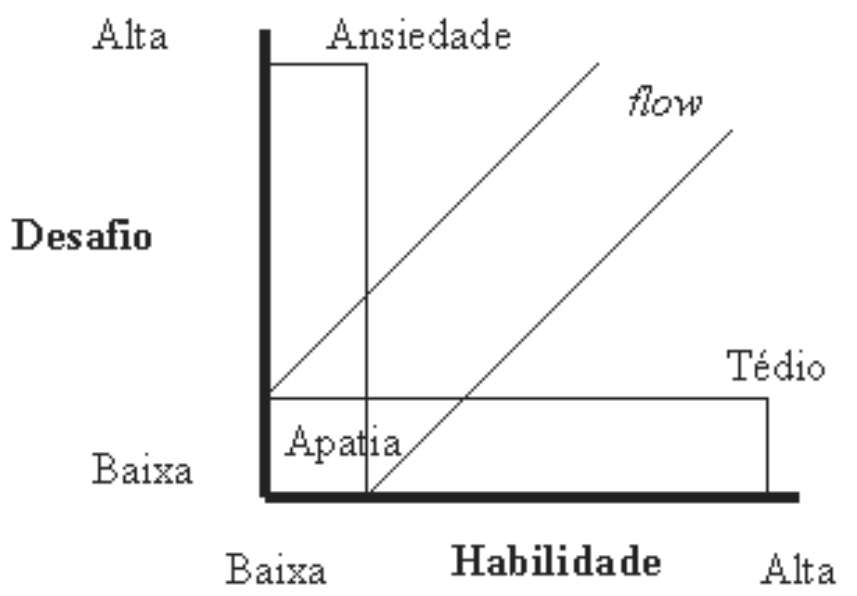

Figura 1. Relação entre nível de desafio/ habilidade e flow. (adaptado de CSIKSZENTMIHALYI, 1992, p. 113).

- Metas claras e retorno (feedback) das ações: clareza sobre o objetivo a ser atingido, conhecimento das regras, do que é necessário fazer para que a atividade ocorra com sucesso. Ter indicadores efetivos sobre como está sendo o desempenho na tarefa.

- Concentração total na atividade e no momento presente: o foco da atenção está totalmente na tarefa e no presente, não é desperdiçada energia psíquica para processar informações que não sejam pertinentes à realização da atividade.

- Sentimento de 'fusão' entre ação e consciência: o envolvimento na atividade é tão intenso que as ações parecem transcorrer

Movimento, Porto Alegre, v. 15, n. 02, p. 45-68, abril/junho de 2009. 
quase automaticamente, de forma totalmente espontânea e natural, a pessoa deixa de se perceber como distinta das ações que realiza.

- Sensação de controle: no flow, há certa sensação de controle sobre a situação, embora não exista uma preocupação efetiva com isso. Há uma satisfação em exercer o controle sobre si mesmo em situações difíceis ou complexas.

- Perda da autoconsciência: a percepção que temos de um self (a soma dos conteúdos da consciência - lembranças, ações, desejos, prazeres e dores, e a hierarquia de metas que construímos ao longo de nossa vida) separado do mundo à nossa volta deixa de existir. Quando estamos profundamente envolvidos (conectados) com o que estamos fazendo, podemos ter um sentimento de união com as pessoas, coisas ou o ambiente à nossa volta.

- Sentimento de distorção ou perda da noção da passagem do tempo: algumas pessoas descrevem certa desorientação temporal ou perda da noção da passagem do tempo. Algumas relatam uma sensação de que o tempo passou muito rápido, outras que se passou muito mais tempo do que de fato ocorreu.

- Sentimento de viver uma experiência autotélica: para Csikszentmihalyi (1992, p. 103), "o elemento fundamental de uma experiência máxima, ou flow, é que ela tem um fim em si mesma. Mesmo que em princípio seja efetuada por outras razões, a atividade que nos absorve, torna-se um fim em si mesma". O resultado de vivenciar o flow é a percepção de uma "experiência autotélica", capaz de proporcionar um profundo sentimento de prazer e satisfação, o fato de estar ali e poder realizar a atividade é a recompensa.

Dos oito elementos, três deles (equilíbrio entre desafio e habilidade; metas claras e retorno (feedback); concentração total na atividade e no momento) podem ser entendidos como elementos necessários para que o flow ocorra. Os demais (fusão entre ação e consciência; sensação de controle; perda da autoconsciência; perda da noção do tempo; experiência autotélica) podem ser interpretados como consequências ou como percepções da ocorrência do estado mental. Essa divisão visa facilitar a compreensão do fenômeno e a análise de dados no estudo.

Movimento, Porto Alegre, v. 15, n. 02, p. 45-68, abril/junho de 2009. 
Csikszentmihalyi (1999) aponta que as atividades esportivas são potencialmente geradoras do estado de flow. Nelas estão presentes todos os elementos necessários para que oflow ocorra. Constituem atividades que prendem nossa atenção, possuem metas claras, fornecem feedback e representam desafios que devem ser respondidos à altura com determinadas capacidades ou habilidades.

\section{Metodologia}

Analisamos os dados qualitativamente. A forma como os sujeitos interpretavam suas experiências é que tinha relevância para objetivos do estudo. Selecionamos dez praticantes de corrida de rua (seis homens e quatro mulheres), por serem praticantes no momento da seleção e por seu tempo de engajamento na atividade (entre 3 e 46 anos de prática). Os corredores não foram considerados atletas de elite, porque não participavam de provas nessa categoria e tinham outra profissão para seu sustento. Todos praticavam, no mínimo, três vezes por semana e apenas um não participava de provas. Os corredores tinham entre 23 e 64 anos de idade.

Eles receberam inicialmente uma Carta-Convite para participação com informações sobre o tema, forma de coleta de dados e outras orientações. Caso aceitassem, assinavam um termo de consentimento autorizando a utilização dos dados e recebiam também um questionário, com dados pessoais e informações sobre seu envolvimento com a corrida, fornecendo um quadro geral que possibilitou o cruzamento de informações com as respostas fornecidas posteriormente nas entrevistas.

Aplicamos uma entrevistada do tipo semiestruturada, em que os participantes manifestaram suas opiniões de forma oral, seguindo um roteiro básico de perguntas formuladas pelo entrevistador. Todas as entrevistas foram gravadas em aparelho digital e posteriormente transcritas para a análise de conteúdo. O protocolo da pesquisa foi aprovado pelo Comitê de Ética da Faculdade de Ciências Médicas da Unicamp.

Utilizamos o método de análise de conteúdo para análise dos dados, que, segundo Triviños e Molina Neto (2004, p. 159), presta-se

Movimento, Porto Alegre, v. 15, n. 02, p. 45-68, abril/junho de 2009. 


\section{Artigor Orifimais Fábio Massarella e Pedro Winterstein}

ao estudo das motivações, atitudes, crenças, valores e tendências que, à simples vista, não se apresentam com a devida clareza. Para Bardin (1991), a análise de conteúdo é constituída por um conjunto de técnicas de análise das comunicações, que visa, por meio de procedimentos sistemáticos e de descrição objetiva do conteúdo das mensagens, a obter indicadores quantitativos ou não, que permitam a inferência de conhecimento relativo às condições de produção e de recepção das mensagens.

Após a transcrição literal das falas (dados brutos), os mesmos foram separados em grelhas de análise (nove grelhas), sendo uma a resposta dos corredores ao complemento da seguinte frase:"A corrida para mim é:" constante do questionário, que possibilitou uma verificação da consistência das respostas fornecidas nas entrevistas. As outras oito grelhas foram respostas às perguntas diretamente formuladas aos entrevistados, ou levantadas a partir da recorrência nas entrevistas. Foram elas:

1) Quando você começou a se interessar pela corrida e por quê?

2) Por que você corre atualmente?

3) Se deixassem de existir competições, você continuaria correndo?

4) Quais os sentimentos mais comuns quando você está correndo?

5) Quais os pensamentos mais comuns quando você está correndo?

6) Relate uma experiência com a corrida que tenha sido marcante para você.

7) Como é para você participar da mesma prova que atletas de elite?

8) Deixe uma mensagem para as pessoas sobre a corrida.

Agrupamos todas as respostas que tinham relação nessas grelhas, independentemente do momento da entrevista em que apareceram, mas tomando o cuidado de não descontextualizá-las. O próximo

Movimento, Porto Alegre, v. 15, n. 02, p. 45-68, abril/junho de 2009. 
passo foi a separação desses dados dentro das grelhas em unidades de significação (parágrafos ou paráfrases que encerravam um raciocínio do entrevistado). Cada unidade de significação recebeu um número sequencial, para facilitar as etapas posteriores de análise e sua rastreabilidade. Após isso, realizamos um procedimento de interpretação dos dados brutos, visando dar mais clareza à ideia central da fala do entrevistado e possibilitar uma categorização dos mesmos. Atribuímos um código inicial de categoria a cada uma das unidades de significação, e, em seguida, agrupamos as unidades de significação segundo o código de categoria que receberam, mantendo sua numeração inicial. As categorias que emergiram da análise foram: Incentivos (favoráveis - desfavoráveis); Sentimentos (favoráveis - desfavoráveis); Pensamentos (favoráveis - desfavoráveis); Experiências Próprias (positivas - negativas); Experiências Alheias (positivas negativas); Item Informativo.

Nessa etapa, também realizamos uma nova checagem de todas as unidades de significação, agora com os dados interpretados, visando verificar sua compatibilidade com a categoria em que situamos e, caso necessário, fazíamos o seu reenquadramento em outra categoria de análise.

A próxima etapa foi a separação e o agrupamento das unidades de significação por temas, que foram quantificados por número de vezes que apareceram e durante qual entrevista.

\section{ANÁLISE DE DADOS E DISCUSSÃo}

As experiências, os sentimentos e os pensamentos que os praticantes declararam ter com a corrida, analisamos, sob a óptica das teorias da motivação intrínseca e do flow. Também buscamos identificar possível relação dos itens analisados com a permanência deles na atividade por longo período de tempo.

Inicialmente procuramos identificar quais motivos os levaram a escolher a corrida como modalidade esportiva para praticarem, $o$ que consideram que os influenciou inicialmente em seu engajamento nessa atividade. A resposta que os praticantes citaram com maior

Movimento, Porto Alegre, v. 15, n. 02, p. 45-68, abril/junho de 2009. 


\section{Artigos Originais Fábio Massarella e Pedro Winterstein}

frequência (quatro praticantes), foi a influência de alguém com quem existia um vínculo afetivo, como pais, irmãos, namorados ou amigos. Podemos relacionar essa resposta com o motivo de filiação, definido como: "[...] desejo de estar em relações afetuosas e amistosas com as pessoas" (MURRAY, 1978, p.159). Esse motivo parece ter sido determinante para que essas pessoas aderissem à atividade.

A segunda resposta mais frequente, citada em três entrevistas, foi a vivência da corrida na escola, durante as aulas de Educação Física. Uma das pessoas também citou a influência da prática da corrida em uma instituição militar. Isso denota a importância da vivência das atividades físicas e esportivas na escola ou em programas que promovam a participação e a inserção das pessoas. É preciso criar oportunidades para que o maior número de pessoas vivencie atividades físicas e esportivas, despertando a motivação inicial para que possa ocorrer o interesse e o engajamento em alguma delas. $\mathrm{O}$ ambiente escolar, os clubes, as associações e programas ligados às prefeituras ou a outras entidades, têm um papel bastante importante nesse aspecto.

Um dos praticantes informou ter iniciado a corrida por indicação médica, foi orientado a fazer uma atividade aeróbica em função de problema de saúde e optou pela corrida. A conscientização dos benefícios à saúde decorrente da prática regular de atividades físicas e esportivas, demonstra papel importante para que as pessoas adotem um estilo de vida ativo. Esse motivo parece ter relação com o motivo de evitação de danos, que seria, segundo Murray (1978, p.152), a necessidade de evitar dores, lesões físicas, doenças ou a morte.

Outro praticante revelou ter iniciado a pratica da corrida por ser uma modalidade esportiva individual, na qual as decisões e consequências teriam relação apenas consigo próprio, sem depender de outros. Esse aspecto parece ser coerente com o motivo de autonomia, definido por Murray (1978, p.152) como a necessidade de emanciparse, libertar-se de restrições, resistir à coerção. Evitar ou abandonar atividades prescritas por autoridades prepotentes. Ser independente e livre para agir de acordo com a própria vontade.

Movimento, Porto Alegre, v. 15, n. 02, p. 45-68, abril/junho de 2009. 
Podemos inferir que, para a adesão inicial à atividade física, o incentivo externo tem papel importante. Oito praticantes apontaram que iniciaram a prática da corrida por influência de alguém próximo ou pela vivência da corrida na escola ou em outra instituição e um por indicação médica, todos motivos extrínsecos à atividade.

Também foi possível identificar, através das análises das entrevistas, que nem sempre os motivos que levaram os participantes a se engajarem na corrida foram os mesmos apontados por eles como responsáveis por sua permanência, ou então, que outros motivos somaram-se ao motivo original. Para alguns, o motivo de filiação, por exemplo, parecia ser ainda um direcionador do comportamento com relação à atividade, sendo acrescido de outros motivos. Para outros, no entanto, outros motivos adquiriram maior expressividade, como o motivo de realização, definido por Murray (1978, p.153) como a necessidade de realizar algo difícil, vencer obstáculos e atingir um alto padrão de desempenho, superar a si mesmo ou outras pessoas. As pessoas se sentem motivadas a melhorar seu desempenho pessoal na corrida, ou se esforçam para manter o nível de desempenho que atingiram. Elas estabelecem padrões de qualidade e procuram medir qualitativamente seu rendimento.

Outro motivo muito presente no discurso dos corredores que parece estar muito relacionado ao engajamento deles na corrida, é o de atividade lúdica, que Murray (1978) define como a necessidade de agir por divertimento, sem outro propósito. Procurar um relaxamento gostoso das tensões, participar de jogos, esportes, dança etc. Esse motivo parece ser também um direcionador importante do comportamento demonstrado pelos entrevistados.

Nem sempre os motivos que levaram os praticantes a iniciarem a atividade foram reconhecidos por eles como responsáveis por sua permanência, ou então os motivos originais somaram-se a outros, reforçando o comportamento de engajamento na atividade. Para Murray, nem todas as pessoas apresentam todos os motivos ou todas as necessidades que ele reconheceu existir, podemos sentir todas ao longo da vida, assim como jamais sentir algumas delas (SCHULTZ; SCHULTZ, 2002).

Movimento, Porto Alegre, v. 15, n. 02, p. 45-68, abril/junho de 2009. 


\subsection{TENDÊNCIA MOTIVACIONAL INTRÍNSECA OU EXTRÍNSECA}

Analisamos, nas respostas, o que os praticantes apontaram como as principais razões que os mantinham engajados na corrida, procurando identificar se apresentavam tendência motivacional intrínseca ou extrínseca com relação à atividade. No questionário que responderam, foi solicitado que completassem a frase: "A corrida para mim é:". A resposta complementava a análise dos discursos obtidos nas entrevistas. Também solicitamos que deixassem uma mensagem para as pessoas sobre a corrida, em quem poderiam deixar transparecer o que era agradável e recompensador em sua prática, tentando passar às pessoas tal conteúdo. Os dados obtidos deram elementos para avaliar qual a tendência motivacional predominante nos entrevistados. O quadro 1 mostra os temas agrupados dentro das categorias, quantificados por número de vezes em que apareceram durante as entrevistas.

\begin{tabular}{|c|c|c|c|c|c|c|c|c|c|c|c|}
\hline Motivação Intrínseca & \multicolumn{11}{|c|}{ Praticante } \\
\hline Temas & 1 & 2 & 3 & 4 & 5 & 6 & 7 & 8 & 9 & 10 & $\%$ \\
\hline Empenho, determinação, comprometimento. & 4 & 7 & 6 & 3 & 6 & 6 & 4 & 8 & 8 & 10 & 100 \\
\hline Bom desempenho, boa colocação em provas. & 2 & 7 & & 13 & 5 & 20 & 12 & 11 & 15 & 6 & 90 \\
\hline $\begin{array}{l}\text { Sentimento de necessidade, de parte integrante da } \\
\text { vida ou do estilo de vida. }\end{array}$ & 1 & 1 & 8 & 3 & 2 & & 1 & 4 & 5 & 10 & 90 \\
\hline $\begin{array}{l}\text { Sentimento de bem-estar, maior disposição física e } \\
\text { mental decorrentes da corrida. }\end{array}$ & 6 & 1 & 9 & 4 & 2 & & 4 & 1 & 3 & & 80 \\
\hline Sentimento de superação, de conquista. & 8 & 8 & & & 9 & 5 & 8 & 4 & 3 & 5 & 80 \\
\hline $\begin{array}{l}\text { Momento para organizar a vida, pensar na familia, } \\
\text { trabalho, dia-a-dia. }\end{array}$ & & 3 & 1 & & 3 & 7 & 1 & & 7 & 5 & 70 \\
\hline Sentimento de liberdade, de estar junto à natureza. & 3 & 7 & 2 & & & & 5 & & 2 & & 50 \\
\hline Sentimento de fazer algo de que gosta. & 4 & 4 & 1 & & 1 & & 1 & & & & 50 \\
\hline O fato de ser um esporte individual. & & 4 & 3 & 1 & & & & & 2 & & 40 \\
\hline Sentimento de missão cumprida, de dever cumprido. & 1 & & & & & 1 & 1 & & 1 & & 40 \\
\hline Sentimento de gratidão por poder correr. & 2 & & & & & & 1 & & & & 20 \\
\hline Ter qualidade de vida. & & & & & & & 4 & & & & 10 \\
\hline Pensar em grandes atletas para se motivar. & & & & & & & & & & 2 & 10 \\
\hline
\end{tabular}

Quadro 1. Temas relacionados à motivação intrínseca para a corrida (número de vezes que surgiram nas entrevistas).

Todos esses itens são sentimentos relacionados ou decorrentes da prática, ou refletem a maneira como os sujeitos se relacionam com a corrida em função dos sentimentos e dos pensamentos envolvidos, caracterizam, assim, tendência motivacional intrínseca para a prática da corrida.

Movimento, Porto Alegre, v. 15, n. 02, p. 45-68, abril/junho de 2009. 


\begin{tabular}{|c|c|c|c|c|c|c|c|c|c|c|c|}
\hline Motivação Extrínseca & \multicolumn{10}{|c|}{ Praticante } \\
\hline Temas & $\mathbf{1}$ & $\mathbf{2}$ & $\mathbf{3}$ & $\mathbf{4}$ & $\mathbf{5}$ & $\mathbf{6}$ & $\mathbf{7}$ & $\mathbf{8}$ & $\mathbf{9}$ & $\mathbf{1 0}$ & $\mathbf{\%}$ \\
\hline Expectativa de obter benefícios para saúde. & 1 & & 3 & 4 & 3 & 1 & 2 & 3 & 1 & 3 & 90 \\
\hline Incentivo de alguém próximo. & 3 & 5 & & 3 & 2 & 2 & 8 & 2 & 1 & & 80 \\
\hline Convivência ou inserção num grupo. & & 9 & & & & 12 & 3 & 1 & 2 & 11 & 60 \\
\hline Emagrecimento, perda de peso. & 2 & 2 & & 4 & & 5 & 1 & & & & 50 \\
\hline Participação dos atletas de elite nas provas. & & & & & & & 1 & 2 & 3 & 5 & 40 \\
\hline Incentivo de outras pessoas nas provas. & 1 & & & & & & & & 1 & 1 & 30 \\
\hline Amizade e união entre os corredores. & 2 & & & & & & & & 3 & 1 & 30 \\
\hline
\end{tabular}

Quadro 2. Temas relacionados à motivação extrínseca para a corrida (número de vezes que surgiram nas entrevistas).

Os temas do quadro 2 relacionavam-se à motivação extrínseca, porque representavam algo que obtemos como recompensa pela prática, ou algo que esperamos obter dela. Dependendo do grau de importância que a pessoa atribui a eles, sua ausência pode interferir negativamente em sua motivação para a prática.

Devemos levar em consideração que as recompensas extrínsecas podem contribuir para o fomento da motivação intrínseca, desde que sejam percebidas pelas pessoas como prêmio, não como um elemento controlador do seu comportamento (WEINBERG; GOULD, 2001). É o caso dos elementos extrínsecos encontrados nos discursos, eles são vistos como um prêmio pelo envolvimento com a atividade, não como algo recebido para controlar seu comportamento ou o seu rendimento.

Pela análise, verificamos que todos os praticantes tinham tendência motivacional intrínseca com relação à atividade. Isso aponta para uma relação importante entre a tendência motivacional intrínseca e o engajamento e a permanência desses corredores na atividade.

\subsection{ESTADO MENTAL FLOW DURANTE A PRÁTICA DA CORRIDA DE RUA}

Analisamos, nesta etapa, os aspectos presentes nos discursos dos praticantes, que poderiam favorecer a ocorrência de um estado mental de profundo envolvimento na atividade como oflow, e inferir

Movimento, Porto Alegre, v. 15, n. 02, p. 45-68, abril/junho de 2009. 


\section{Artifos Originais Fábio Massarella e Pedro Winterstein}

se esses praticantes vivenciavam um estado mental similar em suas experiências com a corrida.

Para a obtenção dos dados que possibilitassem a análise, realizamos os seguintes questionamentos aos participantes: quais os sentimentos mais comuns que percebiam quando estavam correndo, quais os pensamentos, e a descrição de uma experiência com corrida que tenha ficado marcada na memória como muito gratificante, independentemente de ter sido num treino ou numa competição. Os sentimentos e pensamentos que os corredores percebiam durante a atividade, poderiam indicar elementos importantes com relação à vivência de um estado mental diferenciado como oflow, e as experiências mais significativas para eles poderiam revelar momentos de profundo envolvimento e satisfação com a corrida, coerentemente com a teoria.

Buscamos identificar se os temas que surgiram na análise (Quadro 3), tinham alguma relação com os elementos do flow, ou seja, se eles indicavam que os praticantes mantinham um equilíbrio entre o desafio que a corrida representava e a capacidade de responder a ele, se ficavam totalmente imersos na atividade e focados no momento presente, se mantinham suas metas claras e buscavam obter feedback para avaliar o resultado de suas ações.

\begin{tabular}{|c|c|c|c|c|c|c|c|c|c|c|c|c|}
\hline & Motivação Extrínseca & \multicolumn{7}{|c|}{ Praticante } \\
\hline Dimensão do flow & Tema levantado na análise & $\mathbf{1}$ & $\mathbf{2}$ & $\mathbf{3}$ & $\mathbf{4}$ & $\mathbf{5}$ & $\mathbf{6}$ & $\mathbf{7}$ & $\mathbf{8}$ & $\mathbf{9}$ & $\mathbf{1 0}$ & $\mathbf{\%}$ \\
\hline $\begin{array}{c}\text { Equilibrio entre o desafio } \\
\text { e a habilidade ou a } \\
\text { capacidade. }\end{array}$ & $\begin{array}{c}\text { Percepção realista das capacidades } \\
\text { e situações. }\end{array}$ & $\mathbf{3}$ & $\mathbf{5}$ & & $\mathbf{1}$ & $\mathbf{5}$ & $\mathbf{2 2}$ & $\mathbf{5}$ & $\mathbf{5}$ & $\mathbf{1 0}$ & $\mathbf{8}$ & $\mathbf{9 0}$ \\
\cline { 2 - 12 } & $\begin{array}{c}\text { Facilidade com relação à realização } \\
\text { da atividade. }\end{array}$ & 2 & 3 & 2 & & 8 & & & & 40 \\
\hline $\begin{array}{c}\text { Metas claras e retorno } \\
\text { (feedback). }\end{array}$ & $\begin{array}{c}\text { Objetivos e metas a serem } \\
\text { cumpridos. }\end{array}$ & 4 & 5 & 1 & 3 & 12 & 2 & 4 & 1 & & 80 \\
\hline $\begin{array}{c}\text { Concentração total na } \\
\text { atividade e no presente. }\end{array}$ & $\begin{array}{c}\text { Manutenção do foco na atividade e } \\
\text { no momento presente. }\end{array}$ & 6 & 1 & 7 & 3 & 3 & 5 & 1 & 7 & 6 & 11 & 100 \\
\hline
\end{tabular}

Quadro 3. Número de vezes que os temas relacionados aos elementos necessários para que oflow ocorra surgiu nas entrevistas.

- Equilíbrio entre desafio e habilidade: a percepção dos corredores sobre os desafios que a corrida representa e a percepção da

Movimento, Porto Alegre, v. 15, n. 02, p. 45-68, abril/junho de 2009. 
capacidade de responder a eles, constitui um elemento importante para a que a experiência do flow ocorra. Dois temas surgidos nas entrevistas indicavam relação com essa dimensão: a percepção realista da própria capacidade e das situações (nove entrevistas) e a percepção de certa facilidade com relação à prática da atividade (quatro corredores).

O primeiro tema, percepção realista das próprias capacidades e das situações, tem uma implicação importante nessa dimensão do flow, somente com uma percepção realista do que somos capazes de fazer e do desafio com o qual estamos lidando, é possível vivenciar momentos de plena satisfação e total envolvimento com a atividade. A figura 1 (página 47) mostra que, se estivermos diante de um desafio que julgamos além de nossas habilidades, ficaremos ansiosos, se estivermos envolvidos com um desafio que identificamos como muito abaixo de nossas habilidades, ficaremos entediados.

Quanto ao segundo tema, facilidade com relação à atividade, não significa exatamente que a tarefa fosse fácil para os praticantes, apesar deles poderem estabelecer graus muito variados de dificuldade na corrida (variando percurso, ritmo, duração, relevo etc.), o que eles apontaram foi a percepção pessoal de possuírem certa aptidão natural para a corrida. Inferimos que essa dimensão do flow esteve presente no discurso de todos os corredores através de um ou de outro tema, sendo que alguns deles apontaram os dois temas relacionados a ela.

- Metas claras e retorno (feedback): ter objetivos claros em mente permite adequar as ações às exigências da tarefa e ter clareza sobre a contribuição ou não de suas ações para atingir o objetivo. Ter objetivos claros representa oportunidade para usar e para refinar as habilidades pessoais (IAOCHITE, 1999, p. 31). Oito participantes demonstraram ter muito claro os objetivos e as metas perseguidos na corrida, seja nos treinos ou nas competições. Os corredores procuravam fazer um monitoramento (feedback) para avaliar se estavam conseguindo atingir as metas que estabeleciam, utilizavam instrumentos como cronômetro, frequencímetro, controlavam o tempo a cada

Movimento, Porto Alegre, v. 15, n. 02, p. 45-68, abril/junho de 2009. 


\section{Artigor Orifinais Fábio Massarella e Pedro Winterstein}

quilômetro utilizando planilhas de treino etc. É importante ter consciência de qual é o objetivo na atividade, seja durante um treino ou prova, e ter meios de avaliar se irá conseguir atingi-lo. Essa dimensão do flow esteve presente no discurso de oito entrevistados.

- Concentração total na atividade realizada e no momento presente: a concentração plena na tarefa e no presente impede que a atenção seja desviada para informações sem relevância. Em nosso cotidiano, dificilmente estamos plenamente focados no que fazemos, geralmente realizamos uma atividade pensando em coisas que têm pouca relação com sua execução. As preocupações e ansiedades geralmente tomam conta de nossa mente. Para Csikszentmihalyi (1992, p. 91) essa é a razão pela qual o flow melhora a qualidade da experiência, as exigências claramente estruturadas da atividade impõem uma ordem na consciência, impedindo a desordem comum.

Os praticantes demonstraram conseguir, em várias situações, manter o foco de sua atenção totalmente na corrida, em especial nas provas, eles indicaram que, em especial, na competição, geralmente mantêm-se totalmente imersos no presente. Nos treinos, as respostas variaram bastante. Alguns disseram conseguir focar-se totalmente na corrida, outros, que, em certos momentos, pensamentos e sentimentos não relacionados aparecem, como organização diária, família, trabalho etc. Os praticantes também pontuaram que nos treinos realizados em grupo, as conversas favorecem a dispersão do foco da atenção.

Esses são os três elementos fundamentais para que a experiência do flow ocorra, sendo possível identificá-los no discurso da maioria dos entrevistados, sugerindo que esses corredores podem realmente ter vivenciado um estado mental como oflow. Isso foi verificado através da análise das demais dimensões.

Buscamos analisar os temas que pudessem ter relação com as percepções dos entrevistados por Cskszentmihalyi e outros pesquisadores quando vivenciavam um estado mental como o flow (Quadro 4): fusão entre ação e consciência; percepção de controle; perda da autoconsciência; perda da noção do tempo; experiência autotélica.

Movimento, Porto Alegre, v. 15, n. 02, p. 45-68, abril/junho de 2009. 


\begin{tabular}{|c|c|c|c|c|c|c|c|c|c|c|c|c|}
\hline & Motivação Intrínseca & \multicolumn{11}{|c|}{ Praticante } \\
\hline Dimensão do flow & Tema levantado na análise & 1 & 2 & 3 & 4 & 5 & 6 & 7 & 8 & 9 & 10 & $\%$ \\
\hline \multirow{2}{*}{$\begin{array}{l}\text { Fusão entre ação e } \\
\text { consciência. }\end{array}$} & $\begin{array}{c}\text { Sentimento de realizar a atividade sem } \\
\text { despender grandes esforços. }\end{array}$ & 1 & & & & & 4 & & 2 & & & 30 \\
\hline & $\begin{array}{l}\text { Sentimento de esquecer-se do mundo, } \\
\text { de si mesmo, dos problemas, de curtir o } \\
\text { momento. }\end{array}$ & 8 & & & & & & & & 1 & 2 & 30 \\
\hline Sentimento de controle. & Sentimento de controle na situação. & & 1 & & & & 9 & & 1 & 1 & 2 & 50 \\
\hline \multirow{3}{*}{ Perda da autoconsciência. } & $\begin{array}{l}\text { Sentimento de autoconfiança, } \\
\text { autoestima. }\end{array}$ & 1 & 2 & & & & & 4 & 2 & & 1 & 50 \\
\hline & $\begin{array}{l}\text { Sentimento de igualdade, união com os } \\
\text { outros corredores ou com o ambiente. }\end{array}$ & 1 & & & & & & & & & & 10 \\
\hline & $\begin{array}{c}\text { Sentimento de paz interior, calma, } \\
\text { tranquilidade, relaxamento, tipo terapia. }\end{array}$ & 3 & 3 & 10 & 4 & 4 & 1 & 2 & 6 & 2 & 1 & 100 \\
\hline $\begin{array}{l}\text { Sentimento de transformação } \\
\text { do tempo. }\end{array}$ & $\begin{array}{l}\text { Sentimento de que o tempo passou } \\
\text { muito rápido. }\end{array}$ & & & & & & & 3 & & 1 & 4 & 30 \\
\hline Experiência autotélica. & $\begin{array}{l}\text { Sentimento de prazer, satisfação, } \\
\text { felicidade, alegria, algo compensador. }\end{array}$ & 21 & 11 & 3 & 4 & 10 & 8 & 9 & 7 & 9 & 8 & 100 \\
\hline
\end{tabular}

Quadro 4. Número de vezes que cada tema relacionado às percepções sobre a ocorrência do flow surgiu nas entrevistas.

- Fusão entre ação e consciência: é um sentimento de profundo envolvimento com a atividade realizada, o que conduz a uma ação automática e espontânea, a pessoa deixa de se perceber como dinâmica distinta da atividade que está realizando.

Dois temas que surgiram nas análises parecem ter relação com essa dimensão do flow: o sentimento de estar realizando a atividade sem despender grandes esforços (citado por três corredores), assemelha-se à descrição de Csikszentmihalyi (1992, p. 85) sobre a percepção das pessoas sobre essa dimensão: "há uma sensação de movimento aparentemente isento de esforço". Os corredores relataram experiências em que tinham o sentimento de que estavam tendo um desempenho muito bom na atividade sem uma percepção de que tivessem que realizar grandes esforços para isso.

Três entrevistados relataram um sentimento de desligar-se do mundo quando estavam correndo, algo e ncontrado em muitos dos exemplos de Csikszentmihalyi (1988, 1992, 1999), sobre essa dimensão do flow. Os corredores colocam isso como um sentimento positivo, agradável e prazeroso. Esses momentos sobressaem na memória dos praticantes como especiais, diferenciados, onde o que importa é

Movimento, Porto Alegre, v. 15, n. 02, p. 45-68, abril/junho de 2009. 


\section{Artifor Orifinais Fábio Massarella e Pedro Winterstein}

a corrida e o que vivem naquele momento. Os problemas, as dificuldades, ficam em segundo plano, não entram no foco da atenção durante esses momentos.

Metade dos entrevistados relatou um desses dois sentimentos, indicando que essa dimensão do flow encontra similaridade em suas experiências.

- Percepção de controle: no flow, pode ocorrer uma sensação de controle, mas sem haver uma preocupação efetiva com isso. Parece que a satisfação vem da sensação de exercer o controle sobre si mesmo em situações difíceis ou complexas, não de exercer o controle sobre a situação em si.

Dos corredores entrevistados, cinco demonstram já ter passado por experiências relacionadas com essa dimensão do flow. Devemos considerar também, que essa sensação de controle está ligada a um sentimento de se sentir preparado fisicamente para a atividade, em particular nas provas. $\mathrm{O}$ fato de ter realizado uma boa preparação pode dar ao praticante uma sensação maior de controle ao acompanhar seu ritmo pelas quilometragens e verificar que está conseguindo manter sua meta, além de maior tranquilidade emocional, por saber que se preparou adequadamente.

- Perda da autoconsciência: esse aspecto do flow pode ser decorrente do profundo envolvimento com a atividade. Não há disponibilidade de atenção para lembrar-se do passado ou preocupar-se com o futuro. Isso é o oposto do que ocorre normalmente em nossa vida, raramente estamos totalmente imersos na atividade que estamos realizando, nossos pensamentos e sentimentos nos levam de um lado para outro; passamos a maior parte do tempo como se estivéssemos sonhando acordados.

Segundo Csikszentmihalyi (1992, p. 100-102), a perda da autoconsciência não significa a perda da consciência, mas que o self, a informação que usamos para representar para nós mesmos quem somos, fica abaixo do limiar de percepção consciente, isso pode levar a uma sensação de que os limites do nosso ser foram ampliados. Por conta disso, depois de uma experiência no flow, a percepção que a

Movimento, Porto Alegre, v. 15, n. 02, p. 45-68, abril/junho de 2009. 
pessoa tem de si mesma pode ser mais forte, mais confiante. Isso tem semelhanças com a relação que os praticantes estabelecem entre a corrida e o sentimento de autoconfiança e autoes-tima melhoradas em função da atividade, que foi apontada por cinco corredores.

Outra manifestação dessa dimensão do flow, é que a percepção de que temos um self separado do mundo à nossa volta deixa de existir. Algumas pessoas descrevem isso como um sentimento de união com o ambiente a sua volta, por exemplo, uma montanha, um time de futebol ou um grupo de competidores. Há relato de um dos praticantes, da percepção de um sentimento de igualdade, de união com os outros corredores durante as provas, o que parece ter relação com essa dimensão.

Uma das consequências também de vivenciar essa dimensão do flow, é uma sensação de tranquilidade e de equilíbrio decorrente da atividade. Csikszentmihalyi (1992, p. 99) menciona que quando a pessoa vivencia essa dimensão, pode perceber algo como uma obliteração passiva do self, um sentimento do tipo "deixar-se levar pela maré". Todos os corredores indicaram em suas respostas que experimentaram um sentimento de relaxamento, de paz, de tranquilidade, quando estavam correndo ou após. Todos os entrevistados relataram vivenciar pelo menos um dos três sentimentos relacionados a essa dimensão do flow. Houve entrevistado que relatou os três sentimentos, e quatro sujeitos relataram dois deles. Essa dimensão do flow parece encontrar, portanto, semelhanças com as experiências vivenciadas pelos praticantes.

- Perda da noção do tempo: quando vivenciam o flow, as pessoas podem ter a sensação de que o tempo transcorreu de maneira diferente da habitual, a sensação de que o tempo transcorreu mais rápido ou mais devagar que o real. Isso mostra o aspecto relativo do tempo, parece haver um tipo de desorientação temporal ou perda da consciência da passagem do tempo. Devido a isso, as pessoas podem passar horas imersas na atividade sem perceber que o fizeram ou terem a sensação de que uma ação que transcorreu em apenas alguns segundos ou minutos, levou muito mais tempo do que o real.

Três corredores mencionaram experiências que deixaram transparecer essa sensação de que o tempo passou muito mais depressa

Movimento, Porto Alegre, v. 15, n. 02, p. 45-68, abril/junho de 2009. 


\section{Artifor Orifinais Fábio Massarella e Pedro Winterstein}

do que de fato havia ocorrido. Por exemplo, em prova com percurso extenso como a meia maratona $(21 \mathrm{Km})$, realizado em mais de duas horas, ou seja, um tempo relativamente longo correndo, um praticante relatou a sensação de que o tempo passou muito rápido, que, quando se deu conta, a prova já havia terminado.

- Experiência autotélica: o sentimento que parece melhor caracterizar a experiência no flow, é que exercer a atividade é a própria recompensa que o indivíduo busca. Quando a experiência é intrinsecamente gratificante, a vida se justifica no presente e não ficamos aprisionados em expectativas de recompensas futuras. Vários relatos dos entrevistados apontaram que eles vivenciam essa dimensão do flow em sua prática. O prazer, a alegria e a felicidade por poder correr, por fazer algo que acreditam valer a pena, aparecem com bastante frequência nos relatos de todos os entrevistados quando falam sobre os sentimentos que têm com relação à corrida e sobre as experiências vivenciadas.

Essa dimensão também é muito significativa para este estudo, porque revela o caráter autossustentador da atividade, na qual o prazer e a satisfação que as pessoas sentem durante a corrida, provavelmente são as recompensas que as mantêm engajadas na atividade, ou seja, motivadas intrinsecamente para continuarem praticando por muitos anos.

Para Csikszentmihalyi (1999, p. 36), os momentos no flow são 'excepcionais'. O termo foi retirado das descrições que as pessoas faziam de momentos que se destacavam como os melhores de suas vidas. No flow, o que sentimos, pensamos e desejamos, se harmonizam completamente. Parecem ser os sentimentos positivos vivenciados na corrida que fazem com que os praticantes renovem por tanto tempo sua opção de continuar correndo.

\section{CONSIDERAÇõES FINAIS}

Os participantes do estudo revelaram a existência de vários motivos responsáveis por seu comportamento de engajamento na prática da corrida, são razões que coexistem e se reforçam. Os motivos não atuam isoladamente, mas conjuntamente, reforçando ou inibindo o comportamento do sujeito com relação à atividade. Os

Movimento, Porto Alegre, v. 15, n. 02, p. 45-68, abril/junho de 2009. 
Profissionais de Educação Física podem tem maior possibilidade de êxito em suas intervenções se reconhecerem os motivos determinantes do comportamento das pessoas, identificando quais reforçam ou inibem o comportamento que desejam incentivar. As razões que se contrapõem ao comportamento de engajamento com relação à atividade devem ser compreendidas e trabalhadas, para que não levem o indivíduo a abandonar a prática.

Algum tipo de incentivo externo (motivação extrínseca) parece ter papel importante para que as pessoas iniciem uma atividade física ou esportiva, elas geralmente começam extrinsecamente motivadas. Programas que incentivem a prática e a vivência de atividades físicas e esportivas em escolas, clubes e outras instituições são muito importantes, por darem às pessoas a oportunidade de experimentar atividades dessa natureza, mas o fomento da motivação intrínseca pode ser crucial para que elas permaneçam engajadas, contribuição a ser dada pelo profissional de Educação Física.

O estudo apontou relação favorável entre a tendência motivacional intrínseca e a permanência na atividade por muitos anos. É interessante que os Profissionais de Educação Física se esforcem em estimular o desenvolvimento deste tipo de motivação em seus alunos ou atletas com relação às atividades, visto que um dos problemas enfrentados com grande frequência é a falta de permanência das pessoas por maior tempo nas atividades físicas.

A vivência durante a prática de atividades físicas e esportivas de experiências afetivas positivas, intensas e significativas como o flow, pode contribuir para manter as pessoas intrinsecamente motivadas. O prazer e a satisfação são recompensas encontradas pelos praticantes, justificando o empenho e o engajamento. Quanto mais as pessoas vivenciam essas experiências, mais tempo e dedicação elas investem na atividade. Um estado mental como oflow realça a experiência na atividade, diferenciando-a das demais experiências cotidianas e leva as pessoas a sentirem a atividade como algo recompensador.

É importante também adequar as expectativas individuais na atividade a real capacidade dos alunos ou atletas, mantendo o equilíbrio harmônico entre desafio proposto e habilidade necessária para

Movimento, Porto Alegre, v. 15, n. 02, p. 45-68, abril/junho de 2009. 


\section{Artifor Originais Fábio Massarella e Pedro Winterstein}

superá-lo. Orientar os praticantes, para que tenham clareza sobre as metas e o que é necessário fazer para se atingir os objetivos desejados, ajudá-los a encontrar formas de obter feedback de seu desempenho a curto, médio e longo prazo, monitorando parcial e globalmente suas ações, identificando se elas estão contribuindo ou não para que atinjam os resultados almejados. Orientá-los para que procurem manter-se focados o maior tempo possível em elementos relacionados à atividade, encontrando estratégias para impedir que fatores externos interfiram negativamente em seus pensamentos e sentimentos. Controlando esses elementos, as pessoas podem ter mais domínio sobre suas experiências mentais, melhorando a qualidade da vivência na atividade e isso pode contribuir para maior engajamento, pela satisfação que traz.

São necessários mais estudos sobre o flow no esporte e nas atividades físicas para compreendermos com mais exatidão sua dinâmica de funcionamento e como obter maior controle pessoal sobre ele, mas as condições de ocorrência podem ser facilitadas por meio da intervenção dos profissionais de Educação Física, conforme apontado no estudo, estimulando os praticantes a utilizarem ao máximo seu potencial, pois o flow tende a ocorrer quando os níveis de habilidade são adequados à demanda da tarefa e esta constitui um verdadeiro elemento de crescimento pessoal e de autoconhecimento.

Movimento, Porto Alegre, v. 15, n. 02, p. 45-68, abril/junho de 2009. 


\begin{abstract}
Intrinsic Motivation and the State Mental Flow in Street Runners

Abstract: This article is a result of the Masters Dissertation held in the University of Physical Education, UNICAMP. Participated in the qualitative study, ten practitioners of running. The methodology used was the analysis of content. Most practitioners began activity motivated by outer circumstances, but the intrinsic motivation showed crucial in residence for many years. Relations have been identified among the topics raised in the analysis and the elements that characterize the state mental flow. These elements can be important setters in the structuring of physical activities, keeping the individual intrinsically motivated, resulting in greater attendance, commitment, time and satisfaction.

Keywords: Psychology. Sports. Running. Motivation.

State mental flow.
\end{abstract}

Motivación Intrínseca y el Estado Mental Flow
em Corredores
Resumén: Este artículo es resultado de tesis de máster
celebrada en Universidad de Educación Física de
UNICAMP. Participó del estudio cualitativo, diez profe-
sionales de raza en calles. La metodología utilizada
fue análisis de contenido. La mayoría de los profesio-
nales comenzó la práctica por motivación exterior, pero
la motivación intrínseca mostrou-se crucial en la práctica
por años. Las relaciones se han identificado algunos
temas planteados en el análisis y elementos que carac-
terizan el estado mental flow. Estos elementos pueden
ser importantes en estructuración de actividades físi-
cas, mantenimiento de la persona motivada, que llevaría
a mayor participación, compromiso, tiempo de práctica
y satisfacción.
Palabras clave: Psicología. Deportes. Carrera.
Motivación. Estado mental flow.

\section{REFERÊNCIAS}

BARDIN; L. Análise de conteúdo. Lisboa: Edições 70, 1991.

CONFEDERAÇÃO BRASILEIRA DEATLETISMO. Site Oficial. Disponível em: <http:/ /www.cbat.org.br/corridaderua>. Acesso em 28 de fev. 2007.

CSIKSZENTMIHALYI, M. A descoberta do fluxo: a psicologia do envolvimento com a vida cotidiana. São Paulo: Rocco, 1999.

CSIKSZENTMIHALYI, M. A Psicologia da felicidade. São Paulo: Saraiva, 1992.

Movimento, Porto Alegre, v. 15, n. 02, p. 45-68, abril/junho de 2009. 


\section{Artifos Originais Fábio Massarella e Pedro Winterstein}

CSIKSZENTMIHALYI, M.; CSIKSZENTMIHALYI, I. S. Optimal experience: psychological studies of flow in consciousness. United Kingdom: Cambridge University, 1988

IAOCHITE, R. T. A prática da atividade física e o estado de fluxo: implicações para a formação do futuro profissional em Educação Física. 1999. 142 f. Dissertação (Mestrado) - Instituto de Biociências, UNESP. Rio Claro, 1999.

LUDKE, M. et al. Pesquisa em Educação: abordagens qualitativas. São Paulo: EPU, 1986.

MASSARELLA, F. L. Motivação intrínseca e o estado mental flow em corredores de rua. 2007. 121 f. Dissertação (Mestrado). Faculdade de Educação Física, UNICAMP. Campinas, 2008.

MASSARELLA, F. L.; WINTERSTEIN, P. J. Motivação intrínseca e estado de flow no esporte e na atividade física. In: CONGRESSO DE CIÊNCIA DO DESPORTO DA FACULDADE DE EDUCAÇÃO FÍSICA DA UNIVERSIDADE ESTADUAL DE CAMPINAS, 1, 2005. Anais... Campinas: UNICAMP, 2005.

MURRAY, E. J. Motivação e emoção. Rio de Janeiro: Zahar, 1978.

SCHULTZ, D. P.; SCHULTZ, S. E. Teorias da Personalidade. São Paulo: Pioneira Thomson Learning, 2002.

TRIVIÑOS, A. N. S.; NETO V. M. (Org.). A pesquisa qualitativa na Educação Física: alternativas metodológicas. Porto Alegre: Editora da UFRGS, 2004.

VALLERAND, R. J. A hierarchical model of intrinsic and extrinsic motivation in sport and exercise. In: ROBERTS. G. C. Advances in motivation in sport and exercise. Champaign: Human Kinetics, 2001. p. 263-319.

WEINBERG, R. S.; GOULD, D. Fundamentos da Psicologia do Esporte e do Exercício. Porto Alegre: Artmed, 2001.

WINTERSTEIN, P. J. A motivação para a atividade física e para o esporte. In: DE ROSE JR. (Org.). Esporte e atividade física na infância e adolescência. Porto Alegre: Artmed, 2002.

Recebido em: 07.12. 2007

Aprovado em: 16.02.2009

Movimento, Porto Alegre, v. 15, n. 02, p. 45-68, abril/junho de 2009 